\title{
Minority ethnic women and cervical screening: a matter of action or research?
}

Lai-Fong Chiu Nuffield Institute for Health, University of Leeds, UK

\begin{abstract}
Concerns over low uptake of cervical screening among minority ethnic women have spurred much research and practical activity to address the problem. Due to theoretical and methodological difficulties, research in this area has tended to focus on the communication deficit of women, without addressing the social context. This has not only hindered a wider theoretical understanding of the problem but, also, has perpetuated ineffective health promotion practice in this area. Using a participatory action research (PAR) approach, the project 'Woman-to-woman: promoting cervical screening to minority ethnic women in primary care', tackled the problem by involving both health professionals and women from the communities. Working in partnership, both professional and lay participants identified the problems from their own perspectives and generated solutions to resolve them. An intervention strategy was formulated in which bilingual women from the communities were recruited as community health educators to provide an informed link between their respective communities and the primary care sector. The outcomes of the intervention were evaluated by all participants. This paper aims to introduce PAR as an alternative approach by presenting an overview of the study. It begins by highlighting some of the common theoretical and methodological problems encountered by researchers; and then introduces the research framework of PAR and describes the research processes. A case observation is presented to illustrate the depth of understanding of the screening processes that can be obtained using this approach. The project has demonstrated that applying PAR cannot only lead to meaningful discoveries and insights into the problem of minority ethnic women and cervical screening, but also change in health promotion practice, which would have been difficult to achieve using a conventional research model. However, this study has also revealed major limitations of PAR, which need to be addressed if the approach is to be further developed.
\end{abstract}

Key words: cancer screening; minority women; participatory action research

\section{Introduction}

It has often been reported that disadvantaged groups, whether defined ethnically or socioeconomically, have difficulties in accessing cancer screening services (Coulter and Baldwin, 1987; Majeed et al., 1994; Pill et al., 1988; Waller et al., 1990). In the UK, the participation rate of minority ethnic women in cervical cancer screening programmes is not known, as there is no systematic

\footnotetext{
Address for correspondence: Lai-Fong Chiu, Nuffield Institute for Health, University of Leeds, 71-75 Clarendon Road, Leeds, LS2 9PL, UK. Email: 1.f.m.chiu@ leeds.ac.uk
}

ethnic monitoring undertaken at the primary care level (Chiu, 1998; WNCCC, 2000). However, low cervical screening uptake rates have been shown in two local studies (Doyle, 1991; McAvoy and Raza, 1988). Low uptake has variously been attributed to minority ethnic women's cultural beliefs, attitudes and lack of information (McAvoy and Raza, 1991; Naish et al., 1994; Rudat, 1994). This information 'deficit' model has consequently formed the basis for many intervention studies targeted at South Asian women. This paper highlights some of the theoretical and methodological problems in this research area and the effects that these have had on improving the theoretical understanding of the phenomenon, and the formulation of 
appropriate interventions in practice. It then goes on to present an overview of a participatory action research project (PAR), 'Woman-to-woman: promoting cervical screening to minority ethnic women in primary care'. The outcomes have demonstrated the dual potential of PAR in advancing the knowledge and practice of minority ethnic women and cancer screening.

\section{Theoretical and methodological problems}

A review of the literature undertaken by the author at the beginning of the study (1994) suggested that research in minority ethnic women and cancer screening suffers from many theoretical and methodological problems. Fundamentally, there has been an inappropriate application of biomedical research methods to the study of social behaviours. The obsession with achieving generalized validity has, for many years, led researchers to focus on a positivistic paradigm (randomized control trials). Although more recently researchers have been encouraged to use different methods for different questions, the legacy of the positivistic approach is still apparent in the theoretical and methodological difficulties for this research area. Some of these difficulties are highlighted below.

\section{Ethnicity as a category}

The diverse and changing population of multiracial Britain has generated problems for researchers in categorizing 'ethnicity' (Bhopal et al., 1991). Social scientists have long debated the difficulties of labelling ethnic groups - the socalled 'battle of the name' (Banton, 1987). Despite this, many researchers continue to use 'ethnicity' as an independent variable without acknowledging the difficulty of its definition (Chaturvedi and McKeigue, 1994; Cole, 1993; Rehman and Walker, 1995), and it is often used interchangeably with 'culture' (Senior and Bhopal, 1994; Sheldon and Parker, 1992). In over objectifying these categories, researchers have failed to acknowledge the diversity and fluidity of minority groups in the contemporary UK context.

\section{Language and cultural variations}

Linguistic and cultural diversity exists both between and within minority ethnic groups. The speech communities that we find in today's Britain have developed as a result of complex migration and settlement patterns (Alladina and Edwards, 1991; Braham, 1982). Many of the minority ethnic communities are bi- or multilingual. For example, a Ugandan Asian may speak English, Gujarati, Hindi or Punjabi and a Vietnamese may speak French, English, Mandarin Chinese or Cantonese. However, among researchers and professionals alike, there exists a widespread ignorance about these speech communities. For example, many outsiders label all languages spoken in the Pakistani community as 'Pakistani' or 'Urdu'. While 'Urdu' is the national language of Pakistan, the fact that the Mirpuri and Punjabi dialects are often used concurrently within communities of Pakistani extraction in the UK is not well known outside these communities (Khan, 1991).

Along with language diversity, diverse religious beliefs, literary and cultural traditions are also evident. There are thriving communities of Muslims, Sikhs, Buddhists and Christians among the South Asian communities. The picture is further complicated by the fact that a substantial proportion of the minority ethnic population is British born (ranging from $28 \%$ in the Chinese, to $84 \%$ in the Blackothers categories) according to the 1991 census (OPCS, 1992). ${ }^{1}$ Moreover, patterns of language use and cultural behaviours differ sharply between first, second, and subsequent generations of the minority ethnic populations (Khan, 1991).

\section{Health beliefs and attitudes}

Based on the implicit assumption that health beliefs and attitudes could influence health actions, qualitative researchers have explored minority ethnic women's health beliefs in relation to cervical screening (Naish et al., 1994). However, health beliefs are frequently conflated with 'ethnicity' (Pfeffer and Moynihan, 1996) and directly linked with negative health behaviours, such as noncompliance with treatment or nonattendance. The assumed unidirectional link between 'ethnicity', health beliefs and health behaviours runs perilously

\footnotetext{
${ }^{1}$ The paper was written before the results of the 2001 census became available.
} 
close to blaming the victim. In addition, the wellknown gulf between professional and lay health beliefs is rarely acknowledged. Since lay people's explanations of the causality of diseases that are based on lived experience are often seen by professionals as misguided, the potential for positive contributions of lay knowledge to enhancing understanding of health behaviour in the cultural context is lost (Popay and Williams, 1996). It is then unsurprising that many health intervention studies targeted at minority ethnic women have been carried out in a didactic manner and are ineffective in improving uptake. The uncritical interpretation of results from this type of research can easily contribute to the generalization and stereotyping of minority ethnic communities.

\section{The formation of the 'deficit' model}

The lack of theoretical debate and conceptual clarity among researchers outlined above has led to an overemphasis on language and culture as barriers to health care. These barriers are then simplistically correlated with lack of knowledge or information among minority ethnic populations, and used to explain low uptake of many health services. In the area of women's cancer screening, these assumptions have led many researchers to focus upon 'deficiencies' in minority ethnic women's knowledge and attitudes as reasons for nonattendance. The 'deficit' model, in which education and social failures of minority ethnic communities are attributed to the inadequacy of appropriate cultural resources, is not new (Cochran, 1997; Mack, 1978; Somervill, 1974; Williams, 1973; Williams, 1980; Williams and Wright, 1992). It has exerted a strong influence on education and social research in both the USA and the UK. Although it has met with challenges, its legacy resonates in much of the biomedical research involving minority ethnic groups. The consanguinity debate and many of the health promotion campaigns, such as the Rickets Campaign and the Asian Mother and Baby Campaign, are examples of this (Ahmad, 1994; Stubb, 1993).

In the area of cancer screening, the 'deficit' model formed the basis for two early studies targeted at South Asian women in Britain (McAvoy and Raza, 1988; 1991) and appears to be implicit in others (Doyle, 1991; Hoare et al., 1994; Kernohan, 1996; Rudat, 1994; ScanLink, 1996). Using a quasi-experimental approach,
McAvoy demonstrated the apparent effectiveness of personal instruction and the provision of information in improving uptake (McAvoy and Raza, 1991). However, negative results were obtained from a randomized controlled trial (RCT) of intervention by link workers aimed at improving uptake of breast screening among South Asian women (Hoare et al., 1994). Although information-giving on its own does not constitute sound health education practice, and the information 'deficit' model is generally recognized as too simplistic (French and Adams, 1986; Tones and Tilford, 1994), it has continued to provide the common underpinning of many intervention studies.

Jepson et al. (2000) has carried out a systematic review on the effectiveness of interventions for increasing screening uptake. Although studies were grouped and critically appraised according to the type of intervention undertaken, and some of these involved personal health education as intervention, no meta-analysis of the results of these studies was performed due to methodological and statistical heterogeneity. Indeed Jepson et al. (2000) cautioned against overinterpretation of the review, as no aggregated effect of the interventions could be calculated. Unlike drug trials, intervention using link/lay workers to affect uptake of screening is inherently complex. True randomization of subjects is impossible; many variables are confounded and difficult to control. These facts beg the question whether a true experimental approach to this phenomenon is appropriate in principle (Bowling, 1997).

The above theoretical and methodological problems and the persistent use of the 'deficit' model have not only hindered the theoretical understanding of the problem, but have also perpetuated ineffective health promotion practice in this area.

\section{Participatory action research (PAR) as an alternative paradigm}

Since Kurt Lewin coined the term, 'action research' (Lewin, 1946), many strands of action research have been developed (Reason, 1994) and are increasingly applied in the NHS (Hart and Bond, 1995; Meyer, 2000). However, in terms of applying PAR to health promotion research in the National Health Service context, the Woman-toWoman Project presented below is the first of its 
kind. Rather than dealing with the phenomenon in the abstract, action research in general requires the study to be grounded in practice, focussing on actors, actions and contexts. PAR specifically requires the involvement and commitment of participants to bring about change of their conditions (Fals-Borda and Rahman, 1991). Limitation of space make it impossible for me to describe in depth the different strands of action research that were synthesized to form the theoretical backbone of the study. However, I would like to make the assumptions of this study explicit. Researching minority ethnic women and cancer screening necessitates the acknowledgement of the political dimension of inequality in health, and for that reason I chose to locate the study in the liberationist tradition of PAR. ${ }^{2}$ The key concepts of participation, empowerment, production of knowledge and social transformation create a theoretical framework within which the social practice (smear taking) grounded in the intercultural context (interactions of the participants, i.e., smear takers, minority ethnic women and the researcher) can be addressed. This framework assumes that the problem (i.e., minority ethnic women and cervical screening) requires changes in professional practice (health research, health providers and health promotion included). Such changes can be brought about by collaborative working with health professionals and by empowering communities to participate in order to bring about change through an iterative and tightly integrated process of knowing and doing.

By presenting only some of the key features and 'findings' of the study, this paper will inevitably give an impression of an oversimplified account of the systematic practice involved in PAR. However, the main aim of this paper is to introduce PAR as an alternative paradigm, which has the potential to challenge the 'deficit' model and to improve health promotion practice and service delivery. Details of the study and of the processual and theoretical knowledge generated through critical reflection upon it, can both be found in the author's research report to the NHS Cervical Screening Services (Chiu, 1998) and in her doctoral thesis (Chiu, 2000).

The premise of action research is change

\footnotetext{
${ }^{2}$ For a succinct description of this approach, see Reason (1994).
}

through the participation of people who are concerned with a particular problem (Reason, 1994). In the context of primary care, the practical goal of the Woman-to-Woman project was to address the problem of low uptake of cervical screening and minority ethnic women in action by involving both women from the communities and health professionals. The project adopted a research framework based on Lewin's steps of planning, acting, observing and evaluating (Lewin, 1946; 1952). It consisted of three key stages: (a) problem identification; (b) solution generation; and (c) fieldwork and evaluation (Figure 1). These key stages allowed participants, including the researcher, to move dynamically between practical and research activities, progressing from involving participants and stakeholders in the reconceptualization of the 'problem', through the stage of facilitating the generation of an intervention strategy and a programme of activities to address the identified problems in practice, to the evaluation of the outcomes of the intervention from a multiple perspective. The research cycle was then completed by the participants reflecting on the lessons learnt from the whole project, with the purpose of reconsidering whether the problems originally identified had been fully addressed and whether new problems had been generated as a consequence of the intervention.

The following research objectives were initially defined to manage change for each stage:

Stage 1: To explore issues involved in promoting cervical screening among minority ethnic women in primary care.

Stage 2: Based upon the findings from stage 1, participants constructed an intervention strategy and a programme of activities to address issues identified.

Stage 3: To implement the intervention and to evaluate its relative successes and limitations.

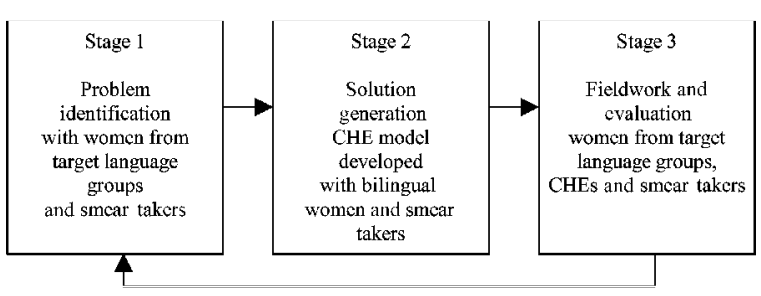

Figure 1 A schematic illustration of the action research framework 
Key research questions arising from the research framework were:

1) What are the perceptions and experiences of cervical screening on the part of the smear takers and minority ethnic women?

2) How are 'problems' in the screening setting defined by different concerned parties? And are these views shared by all parties?

3) What solutions are generated by participants? Are there common themes among the generated solutions?

4) How effective are these agreed solutions when they are put into practice, and what issues arise from such practice?

5) What pragmatic intervention strategy could be formulated through this research to improve cervical screening experiences for minority ethnic women?

\section{Groups involved}

Taking account of the linguistic and cultural diversity within the target communities, language rather than 'ethnicity' was adopted as a tool to organize the women's involvement. Women from six language groups across the three health districts in South Yorkshire (Rotherham, Doncaster and Sheffield) were invited to participate in the project. They were African Caribbean (English/Black English-speaking); Pakistani (Urdu/Mirpurispeaking); Chinese (Cantonese-speaking); Bengali (Syhleti-speaking); and Vietnamese (Cantonese/ Vietnamese-speaking) groups. Smear takers from six general practices were also enlisted to participate in the project. Other stakeholders included health promotion practitioners from respective districts, public health consultants, general practitioners and representatives of community organizations.

\section{Methods}

Although the focus group method was the main vehicle for systematic data collection, the project also utilized data from individual interviews, observations and collective reflections. Materials such as community health educators' (CHEs) contact reports, researchers' field notes, minutes and training flipcharts also provided a rich array of data that supported the interpretation of results. Many data analyses had to be carried out in real-time and fed back to participants for consideration and to guide subsequent actions. A research subgroup involving both CHEs and professionals was set up and met regularly during stage 3 for that purpose.

\section{The generation of 'findings' through the dialectic between action and research}

The description below is an edited version of the action research process in which the progression of the study relies on the dynamic between action and research activities as the project unfolds. Without engaging in a full-blown epistemological debate, readers need to recognize that 'findings' in PAR are often on many different levels. They are not presented as products of absolute knowledge, but have a practical purpose for directing participants' actions for change. In this case, the 'findings' of the preceding stage of the project, for example the contrasting perceptions of the smear takers and minority ethnic women obtained through focus group techniques in stage 1 , were subsequently fedback to participants in stage 2 for facilitating action. This practical use of findings to facilitate action for change can often be an important source of participants' knowledge and empowerment (Rahman, 1991; Tandon and Brown, 1981). Therefore 'findings' presented here were often interleaved in a dynamic process of action and research at each stage as the project unfolds. There is no simple isomorphism between the structures and concepts of PAR and those of conventional research. Readers may find it helpful to refer to the diagrammatic summary of the processes in Figure 2.

In stage 1, bilingual women from the language communities mentioned above were recruited through the author's existing community networks ${ }^{3}$ to participate throughout the research process as coresearchers. Their roles included acting as focus group moderators facilitating focus groups, carrying out individual interviews with minority ethnic women from their own communities and assisting with data analysis. At the same time, a focus group of the six smear takers from the enlisted practices was also conducted to explore their own perceptions of the problem of low uptake of cervical

\footnotetext{
${ }^{3}$ As a health promotion specialist and a long-standing community activist, the author had previously come into contact with many bilingual minority ethnic women from different language groups in the area.
} 


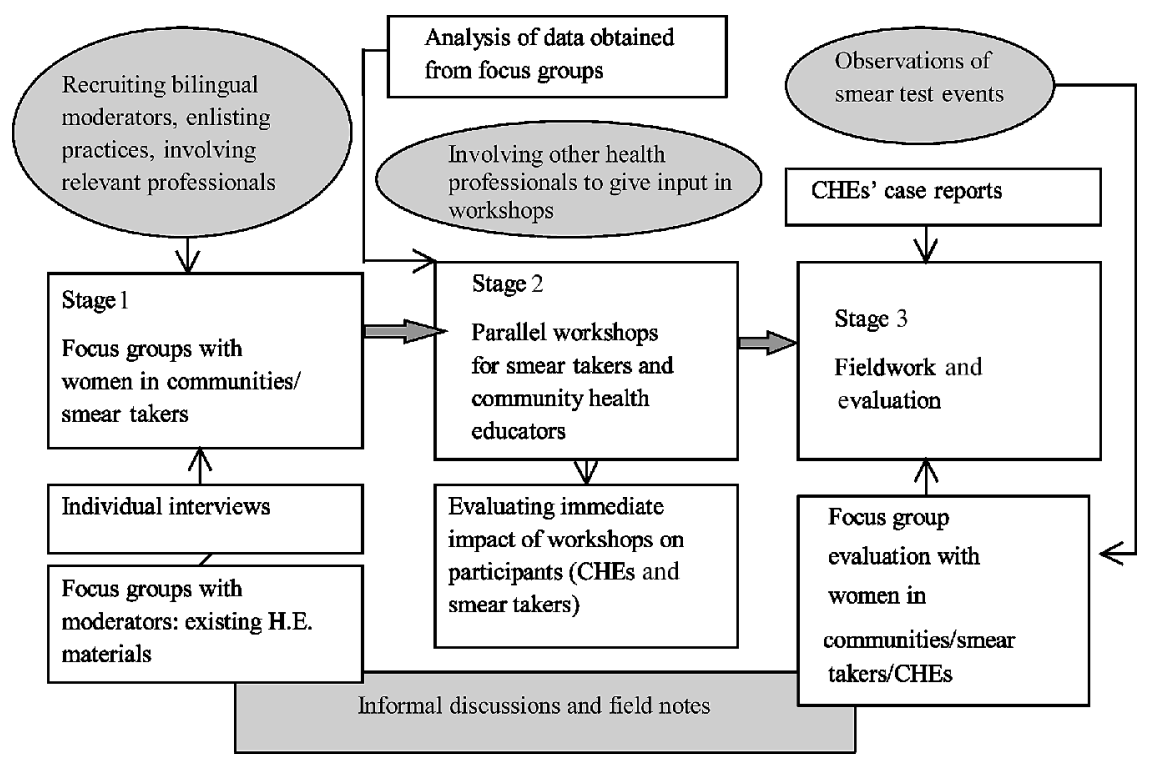

Figure 2 The research process

screening and minority ethnic women. Through these initial focus group discussions, gaps in perceptions between women from the communities and health professionals were identified. The following is a summary of the main findings in Stage $1 .^{4}$

1) Smear takers perceived minority ethnic women as cultural stereotypes who have little interest in preventive health.

2) The majority of minority ethnic women in the study had never received any direct explanation about the purpose of the cervical screening programme or the procedure of the smear test.

3) Women's smear test experiences had by-andlarge been negative and many of them had been screened opportunistically during postnatal examinations. Consequently, many misconstrued the purpose of the smear test as a postal-natal test for cancer of the womb, or confused the smear test and the swab test.

4) Cultural awareness, and community education and support were two major solutions suggested by participants of both the professional group and the language groups.

\footnotetext{
${ }^{4}$ The results from stage 1 were reported in detail in the Journal of Critical Public Health in 1999 (Chiu et al., 1999).
}

The problems identified by the participants suggested that both the lack of explanation of the purpose and procedure of the smear test, and professionals' perceptions and attitudes were significant factors in affecting uptake (Chiu et al., 1999).

Based on the above findings, participants generated a two-pronged intervention strategy. On one hand, the smear takers proposed a workshop programme through which their cultural awareness and intercultural communication skills could be improved. On the other hand, the Community Health Educator Model was accepted as part of the intervention by all participants. Bilingual women who were involved in stage 1 as moderators of the focus groups were invited to be trained as community health educators ${ }^{5}$ to provide an informed link between enlisted practices and their communities, with the purpose of facilitating informed access of minority ethnic women to the cervical screening service.

\footnotetext{
${ }^{5}$ The concept of the community health educator was first developed in an action research project in 1993 (Chiu, 1993) in which bilingual women volunteered as health educators in their neighbourhoods to disseminate the breast screening messages. The bilingual women involved in the Woman-to-Woman project had heard of the model and suggested that they should act as CHEs. The suggestion of having the CHEs work with the practices came from the smear takers involved in the project.
} 
In stage 2, all participants were engaged actively in the development of the strategy. The awareness of the smear takers of their own practices led them to embark on a journey of self-awareness through their voluntarily involvement in a series of workshops in which their perceptions and professional practice in relation to the diversity of the population they served were critically examined and challenged (Chiu, 1998). However, changes in practice did not immediately occur until partnerships between the CHEs and the professionals were established in stage 3. Meanwhile, the bilingual women were transformed into CHEs through an intensive developmental programme (Chiu, 1998; 2000). As a result, CHEs were not only able to act as an informed link between the general practices and their communities to facilitate access to the screening service, but they also took an active part in other developmental health promotion initiatives. Some of the CHEs were able to assist the practices to establish a simple ethnic monitoring system, whereby minority ethnic women who did not attend (DNA) cervical screening were identified in order that CHEs could target their health promotion efforts on them.

In a period of six months (stage 3, fieldwork), the six CHEs carried out 221 prescreening education visits to women in their communities. At the end of the project, two of the six practices reported a $66 \%$ improvement in uptake of cervical screening following the CHEs' visits (Chiu, 1998.). Using a pluralistic evaluation method (Greene, 1994; Springett, 1999), other key qualitative outcomes were defined by all participants involved, and from different perspectives.

For the smear takers, the project has highlighted the need for personal and organizational change to address the issue of low uptake among minority ethnic women. There was a discernible change of perceptions and practice as the results of their participation in the project. The ability to establish equal and legitimate relationships between CHEs and general practices was perceived by the smear takers as a factor for success.

For the CHEs, the development of their role and their critical awareness in promoting health in their communities were crucial. Although many women were supported to gain access to the screening and other services during the project, CHEs questioned the ethics of the lack of sustainability of such a short-term initiative which had the effect of raising expectations of women, but provided no obvious means to meet them in the long run.

Women's reflections on their experiences of the project centred on two major themes, i.e., explanation and communication of cervical screening. Contrary to the stereotype originally espoused by smear takers, that minority women do not pay attention to preventative measures, these women enthusiastically welcomed the educational work CHEs' delivered and stressed the importance of knowing one's own body and how it works. Women who had benefited from the CHEs' support throughout the process from access, diagnosis, treatment to recovery, gave positive responses to the initiative and urged decision-makers to expand the project to cover other health areas. Women came to recognize the qualitative differences when their communication with health professionals was facilitated by the CHEs, rather than by their husbands or relatives, and felt confident in communicating with health professionals. The following case observation taken from stage 3 illustrates how both health professionals' behaviour and communication support can influence minority ethnic women's experience with the screening service.

\section{Case observation}

Mrs Aziz was a recent immigrant who had only arrived in the UK in June 1997. In September 1997, the CHE arranged to accompany Mrs Aziz for a repeat smear, and found that she had already had two smears within the last two months. The smear taker ${ }^{6}$ met Mrs Aziz for the first time, and seemed to be rather confused by her smear test records. She suggested that the repeat smear had been requested by the pathology laboratory due to technical inadequacy shown on previous smears. Subsequently, the CHE and the researcher found that Mrs Aziz had not been informed that during her previous smear procedure a clinical problem had been suspected and that a chlamydia test had been performed on her. As a consequence she had been given treatment without knowing its purpose.

Mrs Aziz showed extreme discomfort and distress during the procedure. She eventually broke

\footnotetext{
${ }^{6}$ Due to the scattered nature of the Yemeni community, it was not always possible to have a perfect match between women and enlisted practices. The smear taker in this case study was not involved in the study and hence had not undergone the training in stage 2 .
} 
down and cried. It was observed that a great part of the communication of the smear taker was instructive, rather than explanatory. The smear taker made no attempt to communicate with the woman about her clinical condition, even though the CHE was present. In addition, the physical environment was far from reassuring. The test was being undertaken in a rather chaotic atmosphere with a continuously ringing phone. On several occasions, male clients attempted to enter the room through the unlocked door. Following her observation of a seemingly 'abnormal' cervix, the smear taker showed signs of panic and made an immediate referral to the colposcopy clinic. In order to allay Mrs Aziz's fear, the CHE promized to accompany her to the colposcopy clinic.

At the colposcopy clinic, Mrs Aziz was still quite disturbed by this referral. It was observed that she was tearful when she was asked to take off her lower garments. The staff in the clinic were involved in the project and had a good understanding of the communication protocol drawn up at stage 2 of this project. Mrs Aziz was informed of the procedure throughout the examination. The steady, clear but quiet explanation given by both the doctor and the nurse had a calming effect on her. Finally, the doctor declared that she detected no abnormality on the cervix. She comforted Mrs Aziz and said she need not be examined for another five years. Mrs Aziz was so relieved that she started to ask the doctor, through the CHE, for contraceptives, as she was anxious not to become pregnant for the thirteenth time. Although the doctor could not prescribe contraceptives, she referred Mrs Aziz to the family planning clinic. Everyone involved felt that this request indicated Mrs Aziz's increased sense of security and trust as a consequence of her experience.

\section{Discussion}

Traditional research scholarship and the hegemony of the positivistic paradigm in biomedicine have influenced much previous research in this area. Due to theoretical and methodological difficulties, research evidence generated, be it quantitative or qualitative, has tended to be contradictory. This has not only hindered a wider theoretical understanding of the problem, but has also perpetuated ineffective health promotion practice in this area.
Practitioners looking towards research evidence to guide their practice are often confused and frustrated by the uncertainty and limitations found (Jepson et al., 2000).

This paper presents PAR as an alternative paradigm within which the problem of low uptake by minority ethnic women of cancer screening can be reconceptualized and addressed through action. Because the framework did not assume the 'deficit model', which ascribes implicit language and cultural deficiencies only to minority ethnic women, we were able to challenge many of the conceptual problems generated by orthodox methods and to reframe the research issue from one of low uptake to one of access, taking the perspective of both smear takers and minority ethnic women. We questioned the simplistic notion of 'information' and demonstrated the complex process of communication involved in the promotion of cervical screening. This study has confirmed that a gulf does indeed exist between professional and lay health beliefs (Pfeffer and Moynihan, 1996). Without explanation being given about the procedure or the purpose of the programme, women's 'patchy' knowledge of the smear test was constructed through their experiences of the service in which they were often screened opportunistically. Instead of understanding how the intersection of religion, culture and the influence of social context affected lay beliefs and behaviour in taking up preventative services, smear takers characterized lay perspectives in relation to preventive measures as 'fatalistic', 'do not take initiatives' and 'it's against their religion'. Professional attitudes found in this study are consistent with previous studies on antenatal screening, sickle cell and thalassaemia services (Anionwu, 1993; Petrou et al., 1990), and appeared to be a cause of dysfunctional communication in the clinical setting (Chiu et al., 1999; Chiu, 2000).

Unlike conventional research, the 'findings' that arise from PAR are not necessarily presented as isolated knowledge through research reports or learned journals. The role of the PAR researcher is to use her 'findings' to facilitate the participants' own critical reflection and examination of their social practice, and to guide their actions for change (McTaggart, 1997; Padilla, 1993). Substantive theoretical resources were brought to bear upon the analysis to aid participants to recognize that their intuitive understanding of the phenomenon was likely to be gendered (e.g., Auberbach and Figert, 


\section{Lai-Fong Chiu}

1995; McBride and McBride, 1981), colonialized, westernized (e.g., Bhavnani, 1993; Brah, 1992; Hooks, 1989) and supplanted by the enculturation of professional practice (e.g., Habermas, 1978; McKie, 1995). The process was crucial for the successful facilitation of the commitments of participants to work for change by developing an intervention strategy based on an understanding of the origins of these contrasting perspectives.

The development of the strategy required that the smear takers work closely with bilingual minority ethnic women to deliver the screening service to those women, who as a social group are socially and politically marginalized and oppressed. Smeartakers needed to be aware of the positional power they and other professionals hold (Novak, 1996) and to honour women's rights as individuals who could identify their own health needs, make their own health choices and take their own actions (Wallerstein and Bernstein, 1988). This required a fundamental shift in the attitude of professionals and a critical rethinking of their role. However, the traditional model of nurse education has the effect of maintaining the status quo, and is likely to be a barrier to critical education (Harden, 1996; Holloway and Penson, 1987). The smear takers' ability to embrace the empowerment approach and work with marginal groups required them to confront the power structure, and to have the courage to seek liberation from it (Stevens, 1989). The workshops in stage $2^{7}$ were designed to develop critical consciousness based upon the pedagogy of Paulo Freire (Freire, 1992), feminist theory and practice (Bhavnani, 1993; Hooks, 1989), and intercultural communication (Stumpf and Bass, 1992). Although we cannot claim that the workshops have brought about lasting change in smear takers' attitudes, it was evident that smear takers were willing to embark on the journey of critical education in which their own beliefs and prejudice were examined and challenged (Chiu, 2000). This process enabled smear takers to change their perceptions and attitudes towards minority ethnic women and to begin to collaborate with the CHEs in solving the problem of low uptake. Meanwhile, the commitment of bilingual women to take on the task of transforming themselves into CHEs for their

\footnotetext{
${ }^{7}$ These include both the designs of the workshops of smear takers and community health educators.
}

respective communities also called for a critical awareness of the power structure in which they found themselves, and to develop the potential symbolic and cultural power ${ }^{8}$ through acquiring the necessary knowledge and skills to broker between communities and services. The power of the CHEs was legitmatized through the establishment of close working relationships between CHEs and smear takers. The intervention strategy developed had not only provided a more appropriate way to influence women's knowledge and behaviour towards preventive health, but also a process for practical change through involvement and sharing of power (Popay and Williams, 1996).

Stage 2 highlights the learning element in PAR, in which intra- and interpersonal change and community action, are interwoven aspects of development towards critical consciousness (Koning and Martin, 1996). The development of the intervention strategy was an example of linking knowing and learning through an iterative process of research and reflection that was necessary for stage 3 , in which participants tested and learnt from their own actions.

The case observation in stage 3 highlights the contrasting experiences and outcomes of Mrs Aziz's encounters with services, with and without the influence of the project. It has given us insights into the impacts of professional behaviours and appropriate communication support on women's screening experience and health-seeking behaviour in the clinical setting. It exemplifies the potential of PAR for gaining rich information and indepth knowledge about the phenomenon that could have not been obtained otherwise.

Change in behaviour, practice and service is seldom unidimensional. The evaluation of the intervention strategy in stage 3 was inclusive of different perspectives. In conventional evaluation, the attribution of values to a particular service or initiative is made mainly by the policy and decision makers. In contrast, PAR acknowledges the

\footnotetext{
${ }^{8}$ Symbolic and cultural power are two concepts of power propounded by Bourdieu, a French sociologist. Symbolic power relates to a conceputalization of all symbolic systems, i.e., art, religion, science and language. Cultural power refers to the individual's wide variety of resources, including verbal facility, general cultural awareness, aesthetic preferences, information about social systems and educational credentials (Swartz, 1997).
} 
inherently political nature of evaluation (Patton, 1987), seeks to promote empowerment and social change as its key values, and prefers participatory methods of evaluation (Greene, 1994). The flexible use of focus group methods to create space for participants to reflect, thus allowing different perspectives on success to emerge, is consistent with the constructivist philosophy that is inherent in PAR (Stringer, 1996). Success of the strategy and the project was not measured against some set of fixed criteria, rather they were determined by the emergent outcomes, be it positive or negative, that were defined and accepted by the participants. Indeed, critical reflection upon participants' own actions in the evaluation stage is an example of linking action and reflection as integral parts of the iterative process of knowing, learning, acting and reflection in PAR.

\section{Limitations of PAR}

Inherent in the adoption of an alternative paradigm is the adoption of another set of beliefs and assumptions about the world and how it can possibly be known (Guba and Lincoln, 1994). Many PAR writers have asserted the primacy of the practical in action research (Fals-Borda and Rahman, 1991; Heron, 1996; Reason, 1999; Toulmin and Gustavsen, 1996). In resisting the building of theories, and placing implicit value on processual knowledge, the presentations of PAR are often reflective but seldom theoretically reflexive (e.g., Cornwall and Jewkes, 1990; Dockery, 1996; McTaggart, 1997; Meulenberg-Buskens, 1996; Seymour-Rolls and Hughes, 1995).

In addition, self-awareness (in terms of the researcher's social position and behaviour in action) within the research process as developed in reflexive ethnography and co-operative enquiry (Altheide and Johnson, 1994; Reason, 1994) is important, as the accounts of such research processes will enable an indepth understanding of process of change and an assessment of the qualities of the researcher in facilitating change in the midst of structural inequalities that are intersected by class, ethnicity and gender (Chiu, 2000; 2001). Unfortunately, the practice of critical reflection in PAR has not been problematised adequately (Holland and Blackburn, 1998). This has led to a major impasse in its theoretical development and in the debate over the different notions of validity. These limitations require PAR researchers to address them urgently.

\section{Conclusion}

Cervical screening among minority ethnic women is a complex social process. It is essentially an intercultural clinical encounter undergirded by power, the understanding of which implicates a whole host of theoretical, methodological and practical issues. Traditional health promotion research and practices focusing entirely on information, language and culture, are at best unproductive and ineffective, and at worst victim-blaming. Using the PAR approach, the Woman-to-Woman project has enabled the 'problem' to be studied in a social context and to be addressed with considered actions.

The cycling between action and research in each stage of the project development, i.e., problem identification, solution generation and fieldwork and evaluation, required the systematic collection of both quantitative and qualitative data. Findings of each stage were used for informing actions of subsequent stages and also for critical and analytical reflection of the project as a whole. The study has demonstrated the practical utilities of PAR by improving professional practices and women's experience of the screening service.

The flexible use of methods has also helped to yield richer data for understanding local conditions, and this in turn has helped to pose questions to many of the theoretical concepts such as information, cultural deficits, ethnicity and health beliefs, and their purported influence on uptake that have underpinned much of previous research in this area.

Last but not least, by involving both bilingual women and smear takers, we were able to enquire into the phenomenon from different perspectives, and uncover some of the barriers that lie beyond language and culture. The quality of professional practice appeared to be a significant factor which may impede or facilitate not only the improvement of uptake in cancer screening, but also access and the quality of service that women experience. Applying PAR to this topic has led to meaningful discoveries in both theoretical and practical domains. However, the lack of dialogue or debate among PAR's supporters on the basic ontological, epistemological and methodological assumptions 
of the paradigm are major obstacles to its further advancement and application in health research.

\section{Acknowledgements}

The author wishes to thank the National Health Service Cancer Screening Programme for its generous financial support. She would also like to thank the minority ethnic women and the health professionals who committed themselves to the project.

\section{References}

Ahmad, W.I.U. 1994: Reflections on the consanguinity and birth outcome debate. Journal of Public Health Medicine 16, 42328.

Alladina, A. and Edwards, V. 1991: Multilingualism in the British Isles, Africa, the Middle East and Asia. London: Longman.

Altheide, D.L. and Johnson, J.M. 1994: Criteria for assessing interpretive validity in qualitative research. In Denzin, N.K. and Lincoln, Y.S., editors, Handbook of qualitative research. London: Sage, 485-99.

Anionwu, E.N. 1993: Sickle cell and thalassaemia: Community experiences and official response. In Ahmad, W.I.U., editor, 'Race' and health in contemporary Britain. Buckingham: Open University Press, 76-95.

Auberbach, J.D. and Figert, A.E. 1995: Women's health research: public policy and sociology. Journal of Health and Social Behaviour (Extra Issue), 115-31.

Banton, M. 1987: The battle of the name. New Community XIV, $170-75$.

Bhavnani, K. 1993: Talking racism and the editing of women's studies. In Richardson, D. and Robinson, V., editors, Introducing women's studies: feminist theory and practice. London: MacMillan, 27-48.

Bhopal, R., Phillmore, P. and Kohli, H. 1991: Inappropriate use of the term Asian: an obstacle to ethnicity and health research. Journal of Public Health Medicine 13, 244-46.

Bowling, A. 1997: Research methods in health: investigating health and health services. Buckingham: Open University Press.

Brah, A. 1992: Women of South Asian origin in Britain: issues and concerns. In Braham, P., Ratansi, A. and Skellington, R., editors, Racism and anti-racism: inequalities, opportunities and policies. London: Sage, 64-78.

Braham, P. 1982: Migration and settlement in Britain: ethnic minorities and community relations, Block 1, Unit 2. Buckingham: Open University Press.

Chaturvedi, N. and McKeigue, P.M. 1994: Methods for epidemiological surveys of ethnic minority groups. Journal of Epidemiology and Community Health 48, 107-11.
Chiu, L.F., editor, 1993: Communicating breast screening messages to minority women. Conference Report. Leeds Health Promotion Service.

Chiu, L.F. 1998: Woman-To-Woman, promoting cervical screening amongst minority ethnic women in primary care, a participatory action research project (1995-97). A research report. Rotherham: Department of Health Promotion, Rotherham Health Authority.

Chiu, L.F., Heywood, P., Jordon, J., Mckinney, P. and Dowell, A. 1999: Balancing the equation: the significance of professional and lay perceptions in the promotion of cervical screening amongst minority ethnic women. Critical Public Health 9, 5-22.

Chiu, L.F. 2000: A participatory action research study of an intercultural communication strategy for improving the experience of cervical screening among minority ethnic women in primary care setting. Unpublished PhD thesis: University of Leeds.

2001: Researching women in primary care: the importance of the self in critical reflection. In Baxter, C., editor, Managing diversity and inequality in health care. Management Challenges Series, London: Baillere Tindall, 87-93.

Cochran, D.L. 1997: African American fathers: a decade review of the literature. Families in Society 78, 340-51.

Cole, M. 1993: 'Black and ethnic minority' or 'Asian, black and other minority ethnic': a further note on nomenclature. Sociology 27, 671-73.

Cornwall, A. and Jewkes, R. 1995: What is participatory research? Social Science Medicine 41, 1667-76.

Coulter, A. and Baldwin, A. 1987: Survey of population coverage in cervical cancer screening in the Oxford region. Journal of the Royal College of General Practitioners 37, 441-43.

Dockery, G. 1996: Rhetoric or reality? Participatory research in the National Health Service, UK. In De Konning, K. and Martin, M., editors, Participatory research in health: issues and experiences. London and New Jersey: Zed Books.

Doyle, Y. 1991: A survey of the cervical screening service in a London district, including reasons for nonattendance, ethnic response and views on the quality of service. Social Science and Medicine 32, 953-57.

Fals-Borda, O. and Rahman M.A., editors, 1991: Action and knowledge: breaking the monopoly with participatory action research. New York: Intermediate Technology/Apex.

Freire, P. 1992: Pedagogy of the oppressed. London: Penguin.

French, J. and Adams, L. 1986: From analysis to synthesis: theories of health education. Health Education Journal 45, $71-4$.

Greene, J.C. 1994: Qualitative program evaluation: practice and promise. In Denzin, N.K. and Lincoln, Y.S., editors, Handbook of qualitative research. London: Sage, 530-44.

Guba, E.G. and Lincoln, Y.S. 1994: Competing paradigms in qualitative research. In Denzin, N.K. and Lincoln, Y.S., editors, Handbook of qualitative research. London: Sage, 530-44.

Hart, E. and Bond, M. 1995: Action research for health and social care: a guide to practice. Buckingham: Open University Press.

Habermas, J. 1978: Knowledge and human interests, 2nd edn, London: Heinemann. 
Harden, J. 1996: Enlightenment, empowerment and emancipation: the case for critical pedagogy in nurse education. Nurse Education Today 16, 32-37.

Heron, J. 1996: Quality as primacy of the practical. Qualitative Inquiry 2, 41-56.

Hoare, T., Thomas, C., Biggs, A., Booth, M., Bradley, S. and Friedman E. 1994: Can the uptake of breast screening by Asian women be increased? A randomized controlled trial of a link-worker intervention. Journal of Public Health Medicine 16, 179-85.

Holland, J. and Blackburn, J. 1998: The research process: Sustaining quality and maximising impact. In Holland, J. and Blackburn, J., editors, Whose voice? Participatory research and policy change. London: Intermediate Technology Publications, 170-77.

Holloway, I. and Penson, J. 1987: Nurse education as a form of social control. Nurse Education Today 7, 235-41.

Hooks, B. 1989: Talking back: thinking feminist, thinking black. Boston: Southend.

Jepson, R., Clegg, A., Forbes, C., Lewis, R., Sowden, A. and Kleijnen, J. 2000: The determinants of screening uptake and interventions for increasing uptake: a systematic review. Health Technology Assessment 4, 14.

Kernohan, E.E.M. 1996: Evaluation of a pilot study for breast and cervical cancer screening with Bradford's minority ethnic women. A community development approach, 1991-1993. British Journal of Cancer 74, Suppl. XXIX, S42-66.

Khan, F. 1991: The Urdu speech community. In Alladina, A. \& Edwards, V., editors, Multi-lingualism in the British Isles, Africa, the Middle East and Asia. London: Longman, 128-140.

Koning, K. and Martin, M. 1996: Participatory research in health: issues and experiences. London and New Jersey: Zed Books.

Lewin, K. 1946: Action research and minority problems. In Lewin $\mathrm{K}$., editor, Resolving social conflicts: selected papers on group dynamics. New York: G.W. Harper and Brothers.

Lewin, K. 1952: Group decision and social change. In Swansan, G.E., Newcomb, T.M. and Hartley, E.L., editors, Readings in social psychology. New York: Henry Holt, 459-73.

Mack C.C. Jr. 1978: Old assumptions and new packages: racism, educational models, and black children. Young Children 33, $45-51$

Majeed, F.A., Cook, D.G., Anderson, H.R., Hilton, S., Bunn, S. and Stones, C. 1994: Using patient and general practice characteristics to explain in cervical smear uptake rates. British Medical Journal 308, 1272-76.

McAvoy, B.R. and Raza, R. 1988: Asian women (1) Contraceptive knowledge, attitude and usage, (2) Contraceptive services and cervical cytology. Health Trends 20, 11-17.

McAvoy, B.R. and Raza, R. 1991: Can health education increase uptake of cervical smear testing among Asian women? British Medical Journal 302, 833-36.

McBride, A.B. and McBride, W.L. 1981: Theoretical underpinnings for women's health. Women and Health 6, 249-68.

McKie, L. 1995: The art of surveillance or reasonable prevention?
The case of cervical screening. Sociology of Health and Illness 17, 441-57.

McTaggart, R. 1997: Guiding principles for participatory action research. In McTaggart, R., editor, Participatory action research: international contexts and consequence. Albany: State University of New York Press, 25-43.

Meyer, J. 2000: Qualitative methods in health-related action research. In Pope, C. and Mays, N., editors, Qualitative research in health care. London: British Medical Journal Publications.

Meulenberg-Buskens, I. 1996: Critical awareness in participatory research: an approach towards teaching and learning. In De Konning, K. and Martin, M., editors, Participatory research in health: issues and experiences. London and New Jersey: Zed Books.

Naish, J., Brown, J. and Denton, B. 1994: Intercultural consultations: investigation of factors that deter nonEnglish speaking women from attending their general practitioners for cervical screening. British Medical Journal 1126-28.

Novak, T. 1996: Empowerment and the politics of poverty. In Humphries, B., editor, Critical perspectives on empowerment. Birmingham: Venture Press.

Office of Population Censuses and Surveys. 1992: 1991 census: Local base statistics. London: OPCS.

Padilla, R. 1993: Using dialogical research methods in group interviews. In Morgan, D., editor, Successful focus groups: advancing the state of the art. California: Sage.

Patton, M.Q. 1987: Evaluation's political inherency: practical implications for design and use. In Palumbo, D.J., editor, The politics of program evaluation. Sage, Newbury Park, California: Sage, 100-45.

Petrou, M., Modell, B., Darr, A., Old, J. et al. 1990: Antenatal diagnosis: how to deliver a comprehensive service in the United Kingdom. Annals of the New York Academy of Sciences 612, 251-63.

Pfeffer, N. and Moynihan, C. 1996: Ethnicity and health beliefs with respect to cancer: a critical review of methodology. British Journal of Cancer 74, Suppl. XXIX, S66-72.

Pill, R., French, J., Harding, K. and Stott, N. 1988: Invitation to attend a health check in a general practice setting: comparison of attenders and nonattenders. Journal of the Royal College of General Practitioners 38, 53-56.

Popay, J. and Williams, G. 1996: Public health research and lay knowledge. Social Science and Medicine 42, 759-68.

Rahman, M.A. 1991: Glimpses of the 'other Africa'. In FalsBorda, O. and Rahman M.A., editors, Action and knowledge: breaking the monopoly with participatory action research. New York: Intermediate Technology/Apex.

Reason, P. 1994: Three approaches to participative inquiry. In Denzin, N.K. and Lincoln, Y.S., editors, Handbook of qualitative research. London: Sage, 324-38.

Reason, P. 1999: Book review: beyond theory: changing organizations through participation. Journal of Occupational and Organisation Psychology, 257-59.

Rehman, H. and Walker, E. 1995: Researching black and minority ethnic group. Health Education Journal 54, 489-500. 
Rudat, K. 1994: Mori health research unit. Report on the health and lifestyles survey on black and minority ethnic groups in England. London: Health Education Authority.

ScanLink. 1996: ScanLink in Newham: report on a year of raising community health awareness. London: ScanLink.

Senior, P.A. and Bhopal, R. 1994: Ethnicity as a variable in epidemiological research. British Medical Journal 309, 327-30.

Seymour-Rolls, S. and Hughes, I. 1995: Participatory action research: getting the job done. Action Research Electronic Reader. <http://www.beh.cchs.usyd.edu.au/ arow/Reader/ rseymour.htm.>

Sheldon, T. and Parker, H. 1992: Use of 'ethnicity' and race in health research: a cautionary note. In Ahmad, W.I.U., editor, The politics of 'race' and health, Bradford: Race Relations Research Unit, University of Bradford, and Bradford and Ilkley Community College.

Somervill, M.A. 1974: Language of the disadvantaged: toward resolution of conflict. Journal of Negro Education 43, 384-401.

Springett, J. 1999: Extract from: Practical guidance on evaluating health promotion, World Health Organisation Regional Office for Europe.

Stevens, P.E. 1989: A critical social reconceptualisation of environment in nursing: implications for methodology. Advances in Nursing Science 11, 56-68.

Stringer, E.T. 1996: Action research: a handbook for practitioners. Thousand Oaks, California: Sage.

Stubb, P. 1993: 'Ethnically sensitive' or 'anti-racist'? Models for health research and service delivery. In Ahmad, W.I.U. editor, 'Race' and health in contemporary Britain. Buckingham: Open University Press.
Stumf, S.H. and Bass, K. 1992: Cross cultural communication to help physician assistants provide unbiased health care. Public Health Records 107, 113-15.

Tandon, R. and Brown, L.D. 1981: Organisation building for rural development: an experiment in India. Journal of Applied Behavioural Science 17, 172-89.

Tones, K. and Tilford, S. 1994: The meaning of success: health education, models and ideologies. In Tones, K., Tilford, S. and Robinson, Y. editors, Health education: effectiveness and efficiency and equity, 2nd edn. London: Chapman and Hall.

Toulmin, S. and Gustavsen, B., editors. 1996: Beyond theory: changing organizations through participation. Amsterdam and Philadelphia: John Benjamins Publishing.

Wallerstein, N. and Bernstein, E. 1988: Empowerment education: Freire's ideas adapted to health education. Health Education Quarterly 15, 379-94.

Waller, D., Agass, M., Mant, D., Coulter, A., Fuller, A. and Jones, L. 1990: Health checks in general practice: another example of inverse care? British Medical Journal 300, 111518.

Williams, C.W. 1980: Issues in the treatment of black families. Smith College Studies in Social Work 50, 179-92.

Williams, R.L. 1973: On black intelligence. Journal of Black Studies 4, 29-39.

Williams, S.E. and Wright, D.F. 1992: Empowerment: the strengths of black families revisited. Journal of Multicultural Social Work 2, 23-6.

Women Nationwide Cancer Control Campaign. 2000: Personal communication. Minority Ethnic Working Group. 